\title{
El epistolario de Gregorio Bermann a Deodoro Roca
}

\author{
The correspondence of Gregorio Bermann to Deodoro Roca \\ A correspondência de Gregório Bermann a Deodoro Roca
}

\author{
María Cristina Vera de Flachs ${ }^{1}$ \\ Universidad Nacional de Córdoba (Argentina) \\ CONICET- CIJS-UE \\ Grupo de investigación HISULA-UPTC
}

Recepción: 25/08/2017

Evaluación: 08/09/2017

Aceptación: 05/01/2018

Artículo de investigación - Reflexión

DOI: https://doi.org/10.19053/01227238.7908

\section{RESUMEN}

El objetivo del presente artículo y su relevancia es dar a conocer algunas cartas privadas hasta hoy desconocidas y enviadas a Deodoro Roca por un intelectual reformista: el Dr. Gregorio Bermann. Para indagar la correspondencia utilizamos el análisis de contenido que permite descubrir el ADN de los mensajes y reconstruir su arquitectura, conocer su estructura, y sus componentes básicos. En síntesis, la correspondencia analizada permite constatar la amistad entre Bermann y Roca a lo largo de sus vidas, la preocupación por la cuestión universitaria y los problemas de la generación del 18.

Palabras clave: Reforma 1918; Universidad de Córdoba; Argentina; Deodoro Roca; Gregorio Bermann, cartas privadas.

1 Doctora en historia por la universidad Nacional de Córdoba - Argentina. Investigadora de CONICET- CIJS-UE - Universidad Nacional de Córdoba- investigadora del grupo HISULA clasificado en COLCIENCIAS categoría A de la Universidad Pedagógica y Tecnológica de Colombia. Correo electrónico: vera@onenet.com.ar 


\section{ABSTRACT}

The aim of this article and its relevance lies in giving to know some private letters, unknown until today, sent to Deodoro Roca by Dr. Gregorio Bermann, a reformist intellectual. To study the correspondence, we used the content analysis that allows to discover the DNA of the messages and reconstructs their architecture, structure, and reveals the basic components. In summary, the analyzed correspondence confirms the friendship between Bermann and Roca throughout their lives, their concerns about the university and the problems of the generation of 1918.

Keywords: Reform 1918; University of Cordoba; Argentina; Deodoro Roca; Gregorio Bermann, private letters.

\section{RESUMO}

O objetivo do presente artigo, bem como sua relevância, é tornar conhecidas algumas cartas privadas, até hoje desconhecidas, e enviadas a Deodoro Roca por um intelectual reformista: o Dr. Gregorio Bermann. Para analisar a correspondência utilizamos a análise de conteúdo, que permite descobrir o DNA das mensagens e reconstruir sua arquitetura, conhecer sua estrutura e seus componentes básicos. Em síntese, a correspondência analisada permite constatar a amizade entre Bermann e Roca ao longo de suas vidas, a preocupação pela questão universitária e as questões da geração de 18 .

Palavras-chave: Reforma de 1918; Universidade de Córdoba; Argentina; Deodoro Roca; Gregorio Bermann, cartas privadas.

\section{INTRODUCCIÓN}

Desde la época colonial hasta la revolución de las comunicaciones en la segunda mitad del siglo XX, las cartas privadas tuvieron la función de tejer las redes de comunicación interpersonal y fueron el medio privilegiado de comunicación escrita entre uno o más remitentes y uno o más destinatarios. Su función pragmática puede abarcar distintas acciones comunicativas que se caracterizan por establecerse a través del discurso epistolar como diferidas en el tiempo y en el espacio. Ellas constituyeron un espacio personal que remitían a la afectividad, los respetos entrañables, los acuerdos o las tensiones que proponían los intervinientes en el pacto epistolar y facilitaron la difusión de noticias familiares o sucesos importantes. En el primer caso, ellas se encargaron de los afectos, los recuerdos y noticias estrictamente privadas. En el segundo caso, el discurso epistolar lleva y trae intereses, preocupaciones literarias o políticas compartidas o acciones comunes, tal el caso de las que analizamos.

Considerada la carta como un género menor, generalmente ha sido poco estudiada, sin embargo, posee una larga tradición y se puede utilizar como fuente para reconstruir la vida o el entorno del personaje a estudiar. Obviamente el interés de la misma reside en su contenido o en los personajes involucrados, lo que nos permite documentar o abordar períodos importantes del biógrafo ${ }^{2}$. Pensada como un diálogo "en ausencia" o como una práctica social de la que

2 Darcie Doll Castillo, “La carta privada como práctica discursiva: Algunos rasgos característicos”, Revista signos 35, No. 51-52 (2002): 33-57.

Nos ocupamos de parte del tema anteriormente en María Cristina, Vera de Flachs, Jorge Gaiteri y Esmeralda "Gregorio Bermann y Lisandro de la Torre a Deodoro Roca”, Revista de la Junta Provincial de Historia de Córdoba, No. 29, (2017): 10. 
participan dos partenaires, cuando se trata de una historia epistolar y no de una correspondencia aislada, la carta tiene una función comunicativa primordial y es esta capacidad de transmisión lo que la diferencia de la función de las memorias o los anales. Como instrumento de escritura al servicio del pensamiento, beneficia el intercambio dialógico entre dos sujetos discursivos que es, a la vez, el lugar en donde la subjetividad del yo toma cuerpo en la palabra escrita. Por eso cuando hablamos de "cartas privadas" nos referimos a la producción, circulación y consumo originales de este género discursivo que inscribe una primera y una segunda persona discursivas, según aparecen configurados en la trama misma del texto epistolar.

En la definición tradicional la "carta personal" remite a la transmisión de un material que principalmente centra su atención en las vivencias personales del enunciador, y que prioriza una temática que revela la trama biográfica de los acontecimientos menores de la vida, es posible pensar también que, desde otra mirada la publicación de la correspondencia privada en forma de epistolarios impone sobre el lector una injerencia del espacio de lo privado en el espacio público ${ }^{3}$.

Otro aspecto relevante para el estudio de las cartas es la doble inscripción que en ellas se producen, a saber: de dos personas (remitente y receptor), dos tiempos diferentes (el de la escritura y el de la lectura), dos espacios geográficos y/o dos intenciones. La necesidad estructural de la carta es la de exhibir esas marcas: de la situación de enunciación y de recepción.

\section{La correspondencia entre amigos}

Los relatos de los laberintos de la vida circulan en la correspondencia emergidos del ejercicio de las responsabilidades y compromisos inherentes a las relaciones de distinto tipo. En la privacidad de una epístola se desnuda la fortaleza o fragilidad de los sentimientos, los reclamos de una amistad o amor y el reconocimiento a la entrega de "nuestros amigos verdaderos". Por lo general, los amigos comparten códigos de intercambio y espacios personales y sociales fuera de los círculos familiares. Esta expansión de los afectos convive con relaciones de civilidad y sociabilidad, de acuerdo a los términos y deberes de un contrato voluntario, en una urdimbre de sentimientos y conductas.

Las cartas personales pueden ser consideradas como prácticas discursivas. Esta perspectiva nos permite analizar las condiciones sociales dentro de las cuales, se concreta el proceso de producción de dichos textos. Podemos pensar así, en un agente social que tiene una posición dentro de la sociedad y por lo tanto posee una determinada competencia. Por eso no solo debemos pensar en el sujeto sino ubicarnos en el lugar desde donde lo hace. Costa y Mozejko nos hablan del "lugar" como principio de definición del agente en su identidad social, al entenderla como competencia para la acción.

3 Tomado de Guiomar Ciapuscio, Tipos textuales, Enciclopedia Semiológica, (Buenos Aires: Facultad de Filosofía y Letras UBA, 1994). 
Dicha competencia abarca en nuestra concepción, dos dimensiones que hacen a la capacidad diferenciada de relación, por una parte, y a la orientación de dicha capacidad o energía. La relevancia otorgada al concepto de lugar obedece a la importancia teórica que reviste la ubicación del agente social en sistemas de relación, en la medida en que su posición definida por el control diferenciado de los recursos en juego es un factor clave en la constitución de su identidad social ${ }^{4}$.

Desde esta perspectiva, no es posible responder a la pregunta de "quién habla" si no identificamos también el lugar desde donde lo hace, puesto que el lugar define al agente. Este aporte nos permite pensar, que quienes enviaron las cartas a Deodoro Roca son agentes sociales activos y competentes, porque se trata de personalidades históricas que fueron parte de la historia política y social de la Argentina, en la primera parte del siglo XX, tal el caso de Gregorio Bermann de quien nos ocupamos en esta oportunidad por ser una personalidad relacionada directamente con el acontecer de la Reforma de 1918 y por su entrañable amistad con el destinatario a lo largo de sus vidas, lo cual pone en evidencia ideales comunes, y la manera en que tejían por este medio epistolar sus planes que luego se convertían en hechos. Sus cartas llevan y traen preocupaciones, planean y, a la vez, expresan afecto y admiración recíproca.

La amistad es un ejercicio de libertad que implica la construcción de un vínculo recíproco y sincero para un fecundo enriquecimiento personal. En el intercambio de miradas y preguntas, se asoman interioridades diferenciadas al desplegarse la autonomía de los sujetos. La ética de la amistad propone un pacto de plena confianza para comunicar proyectos, temores, interrogaciones y reflexiones, tanto sobre lo personal como sobre lo universal y utópico.

Si bien las cartas elegidas fueron escritas pensando que iban a ser leídas en el ámbito privado, dado el tiempo transcurrido y la importancia del tema hemos creído oportuno darlas a conocer hoy. Ellas fueron redactadas en diferentes fechas, formatos y distintos espacios geográficos y hacen al tema en cuestión: esto es el momento de la Reforma de 1918. Por eso las damos a conocer tal cual fueron concebidas, en tanto coincidimos que las cartas son un objeto único y fueron dirigidas de una a otra persona. Su valor es aún mayor en tanto sabemos que Deodoro tiene escasas obras y se refieren a compilaciones póstumas de sus ensayos, discursos, polémicas o apuntes filosóficos o jurídicos. Por otra parte, estas tienen relación con otras cartas incluidas en su epistolario de hombres de la Córdoba de esa época, según se verá.

\section{La técnica de análisis de contenido}

Adherimos en sentido amplio a los conceptos formulados por el Dr. Jaime Andréu Abella ${ }^{5}$ sobre cómo realizar el análisis de contenido de textos, sean escri-

4 Danuta Teresa Mozejko y Ricardo Lionel Costa, "Producción discursiva: diversidad de sujetos", en Lugares del decir. Competencia social y estrategias discursivas (Rosario: Homo Sapiens, 2002), 13-42.

5 Andréu Abela Jaime, "Las técnicas de Análisis de Contenido: Una revisión actualizada", Fundación Centro Estudios Andaluces. De- 
tos, grabados, pintados, filmados, $\mathrm{u}$ otra forma diferente donde puedan existir toda clase de registros de datos, trascripción de entrevistas, discursos, protocolos de observación, documentos, videos,... en tanto el denominador común de todos estos materiales es su capacidad para albergar un contenido que leído e interpretado adecuadamente nos abre las puertas al conocimientos de diversos aspectos y fenómenos de la vida social.

El análisis de contenido se basa en la lectura (textual o visual) como instrumento de recogida de información, que a diferencia de la lectura común debe realizarse siguiendo el método científico, es decir, debe ser sistemática, objetiva, replicable, y válida. En ese sentido es semejante en su problemática y metodología, salvo algunas características específicas, al de cualquier otra técnica de recolección de datos de investigación social: observación, experimento, encuestas, entrevistas, etc. No obstante, lo característico del análisis de contenido y que le distingue de otras técnicas de investigación sociológica, es que se trata de una técnica que combina intrínsecamente, y de ahí su complejidad, la observación y producción de los datos, y la interpretación o análisis de los datos.

Todo contenido de un texto o imagen puede ser interpretado en forma directa y manifiesta, o en forma soterrada de su sentido latente $u$ oculto; indirecto que se sirve del texto manifiesto como de un instrumento, para expresar el sentido oculto que el autor pretendió trasmitir.

Tanto los datos expresos (lo que el autor dice) como los latentes (lo que dice sin pretenderlo) cobran sentido y pueden ser captados dentro de un contexto. El contexto es un marco de referencias que contiene toda aquella información que el lector puede conocer de antemano o inferir a partir del texto mismo para captar el contenido y el significado de todo lo que se dice en el texto. Texto y contexto son dos aspectos fundamentales en el análisis de los mismos.

Por tanto, pertenecen al campo del análisis de contenido todo el conjunto de técnicas tendientes a explicar y sistematizar el contenido de los mensajes comunicativos de textos, sonidos e imágenes y la expresión de ese contenido con ayuda de indicios cuantificables o no. Todo ello con el objetivo de efectuar deducciones lógicas justificadas concernientes a la fuente - el emisor y su contexto - o eventualmente a sus efectos. Para ello el analista tendrá a su disposición todo un juego de operaciones analíticas, más o menos adaptadas a la naturaleza del material y del problema que tratará de resolver, pudiendo utilizar una o varias que sean complementarias entre sí para enriquecer los resultados o pretender así una interpretación fundamentada científicamente.

Antes de comenzar el análisis de cartas de Bermann consideramos necesario incluir una breve referencia biográfica sobre los actores elegidos en esta oportunidad, que demuestra que remitente y receptor fueron representantes de una generación muy particular de la Córdoba reformista. 


\section{Deodoro Roca, la pluma del Manifiesto Liminar}

Roca Deodoro Nicolás, (Luis Jaime del Corazón de Jesús, según acta de bautismo de la Iglesia Catedral de Córdoba), nació en esa ciudad el 2 de julio de 1890, hijo de Deodoro y de Felisa Allende. Casó con María Deheza el 3 de diciembre de 1918, hija del rector conservador de la Universidad, Dr. Julio Deheza, a quien fustigaba con su pluma y de Jerónima Pizarro. Fue padre de Diego Marcelo y de Gustavo. Falleció en la ciudad de Córdoba el 7 de junio de $1942^{6}$.

Estudió en el Colegio Nacional de Montserrat y luego a la Universidad de Córdoba donde se graduó de abogado el 8 de diciembre de 1914 a los 24 años y fue presidente del Centro de Estudiantes de Derecho en 1910. Doctor en Derecho en 1915 con la tesis titulada: Monroe-Drago. A.B.C. Reflexiones sobre la política continental, que fue muy comentada al punto que tuvo una reseña en la revista de Filosofía dirigida por José Ingenieros. El 8 de diciembre de 1915, en el salón de grados de la Universidad pronunció el discurso en representación de los graduados donde hizo referencia a la I Guerra diciendo que,... la tragedia de Europa es algo más que una guerra, allí está ardiendo una civilización. Pensaba que la civilización europea estaba moribunda y que los jóvenes de América debían innovar y pensar en un relevo de esa civilización. También aprovechó la oportunidad para criticar la enseñanza oscura y rutinaria de la Academia.

Desde ese momento se destacó como uno de los jóvenes promisorios de la ciudad, siendo reconocidas sus dotes de orador. Entre los intelectuales que incidieron en Roca en esa instancia se destacan José Martí, Rubén Darío, José Enrique Rodo y José Ingenieros y Ricardo Rojas. En 1917 junto a Arturo Capdevila, fue invitado por el Ateneo de Montevideo para dictar una Conferencia sobre José Enrique Rodo, que fue muy aplaudida ${ }^{7}$. Fue presidente de la Federación Universitaria, desde su constitución (22 de julio de 1914). Redactó el Manifiesto Liminar de la Reforma. Pronunció el discurso cerrando el Congreso Nacional Universitario, el 31 de julio de 1918. Fue designado consejero de la Facultad por la intervención Salinas y docente de Filosofía General.

Años antes había sido director del Museo Provincial Caraffa, durante el primer gobierno radical en la provincia (1916), cargo del que fue exonerado en 1919 luego de "vestir" las estatuas de Córdoba, en repudio a la decisión gubernamental de retirar un desnudo del Salón Oficial de pintura y de prohibir la enseñanza del desnudo artístico en la Escuela Provincial de Bellas Artes. Mientras ejerció ese cargo solicitó al ministro de gobierno que se le permita ocuparse, además del Caraffa, de otro museo que formaría, llamado Museo Social Americano, que abarcaría con preferencia y del modo más completo posible todo lo que se refiere a la etapa precolombina. Fundamentaba esa creación en los hallazgos líticos que se hacían en la provincia y que no tenían lugar físico para ser estudiados y expuestos.

6 "Libro de grados" Archivo del Arzobispado de Córdoba (UNC), Bautismos, Catedral, libro 55, 1890- 1891; y Matrimonios, Pilar, año 1918.

$7 \quad$ La Voz del Interior, 17 de agosto de 1917. 
Ejerció la abogacía con pasión, defendió a estudiantes y presos políticos y fue célebre su participación en el caso de Martita Stud, así como la genial y particular defensa del toro de Ongamira. Sobre su profesión dijo:

"Una vida en plenitud admite y ennoblece el goce espiritual, y enriquece las profesiones que, como la abogacía, están constantemente escapándose de la espiritualidad y cayendo en zonas de decorosa comerciabilidad. Basta para eso orientarla en el sentido de lucha por la justicia y poner en ella valor, pulcritud, decoro, y mantener siempre vivo el horror por la estupidez, por la chabacanería, por el trabajo mal hecho, y por la vulgaridad plebeya y letrada que es pulmón de acero de nuestra profesión. Entonces la abogacía se aproxima a las bellas artes. Y sólo aproximándose así a ellas se puede ser un buen abogado".

Definiendo su actuación, escribió en una mínima autobiografía lo siguiente:

"No he actuado en la vida pública de mi país desde la angostura de programas y partidos politicos" (...) Pero he hecho, al margen de ellos, y desinteresadamente, una intensa y riesgosa vida pública. La haré hasta que me muera, porque me interesa hasta la pasión el destino de la patria y sobre todo el destino del hombre".8.
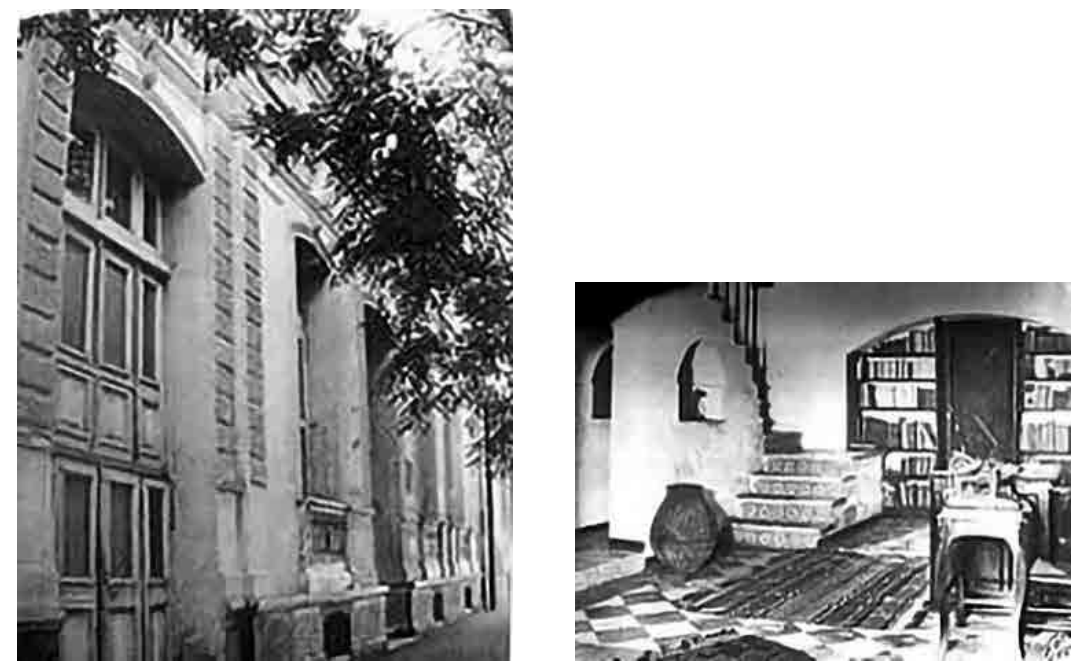

Fuente: autora, frente de la casa y sótano.

Vivió toda su vida en la casa paterna de la ciudad de Córdoba, ubicada en la calle Rivera Indarte 544, en cuyo famoso sótano recibió a personalidades del mundo intelectual y político de su época, entre los que pueden mencionarse a José Ortega y Gasset, Raúl Haya de la Torre, Rafael Alberti, José Ingenieros, Alfredo Palacios, Lisandro de la Torre, Eugenio D'Ors, Waldo Frank, el conde Keyserling, y Stefan Zweig. Y, obviamente, a Gregorio Bermann con quien mantuvo

8 Néstor Kohan, Deodoro Roca, el hereje (Buenos Aires: Editorial Biblos, 1999). 
una sólida amistad a lo largo de sus vidas, como puede leerse en el siguiente punto. Su obra escrita estuvo inicialmente desperdigada en artículos y discursos posteriormente recopilados tras su muerte, como: Las obras y los días (1945), El difícil tiempo nuevo (1956), Ciencias, maestros y universidades (1959) y Prohibido prohibir (1972).

Se le recuerda por su pensamiento y su acción, pero también por la genialidad de su pluma en temas académicos y también cotidianos. Fue co-editor del periódico Flecha, surgido en 1935 en los finales de la Guerra del Chaco, y de la revista Las Comunas, último intento de colaborar con el objetivo de formar al hombre para vivir en democracia.

En síntesis, ¿quién fue Roca? Fue uno de los primeros en articular reclamos pedagógicos y administrativos en la universidad, acordes con la realidad político social argentina. Estaba convencido que la educación y la Universidad debía ser transformada totalmente para ponerlas al servicio de "nuestros hermanos". Primó en él la docencia informal, la simpatía, la gracia y el sentido dionisiaco de la existencia. Pocos políticos tuvieron su claridad y coraje cívico manteniéndose ajenos a partidos y banderías. Se lo consideró una cima moral e intelectual de su época que reaccionaba contra un mundo de oscuras y contradictorias visiones de una realidad a la que embestía y llevaba por delante para superarla dialécticamente sin negar su sentido popular.

Compartimos los conceptos de Ortega y Gasset cuando dijo que Deodoro era el argentino más eminente que había conocido y los de Ezequiel Martínez Estrada quien señaló que fue el escritor político argentino más importante del siglo XX.

\section{El legado de un intelectual reformista: Dr. Gregorio Berman}

\section{Su formación y vida privada}

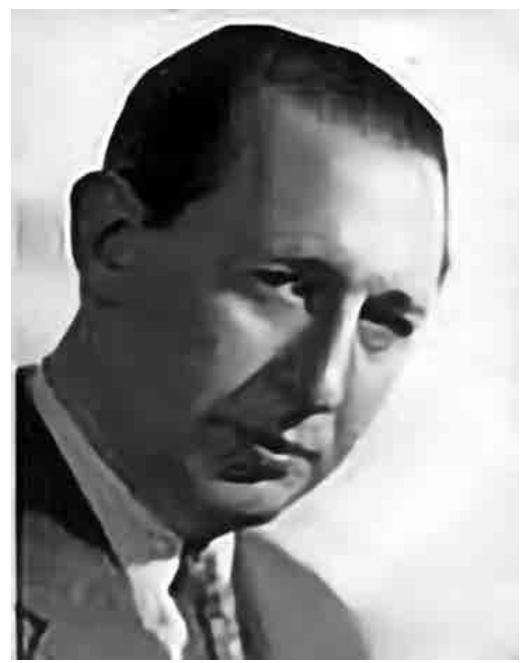

Gregorio nació en Buenos Aires en 1894, era el octavo hijo de una familia de inmigrantes judíos polacos, conformada por Santiago Bermann y Flora Levin, provenientes de una población cercana a Varsovia. La familia hizo un primer intento de asentamiento en el país, más precisamente en Ballesteros (Provincia de Córdoba) donde el padre se dedicó a la agricultura, ocupación que desconocía absolutamente, lo que determinó que la empresa terminara en fracaso ante la pérdida total de la cosecha barrida por una manga de langosta. Decepcionada la familia regresó a Europa, pero cuando los hijos mayores se encontraban en edad de ser llamados a cumplir con el Ser- 
vicio Militar y ante la gravedad que podía resultar esta situación para los judíos, emprendieron nuevamente el camino de la emigración para establecerse esta vez en Buenos Aires, cuando corría el año 1894. En esta ocasión el padre decidió abrir una mueblería y allí fue donde nació Gregorio, único por otra parte originario de Argentina. Desde el inicio de la educación primaria asistió a la escuela pública; parte de la enseñanza secundaria la recibió en el Colegio Sarmiento y en el Nacional Buenos Aires. Se sabe que uno de los motivos que motivaron la elección de los estudios de Medicina, tuvo que ver con la influencia ejercida por su hermano mayor, Samuel, quien llegó a desempeñarse como Profesor en la Cátedra de Obstetricia de dicha casa de altos estudios.

Durante sus años de estudiante tuvo una amplia militancia; desde 1913 participó en la Liga de Educación Racionalista Argentina y colaboró con su órgano la revista La Escuela popular, con el objetivo de difundir esa pedagogía y aunar esfuerzos en la fundación de una Escuela Moderna9. Como alumno de las Facultades de Filosofía y Letras y de la Medicina de la Universidad de Buenos Aires, se preocupó porque entre los jóvenes que asistían a las mismas circulara el cientificismo socialista. En 1917 asumió la dirección de Verbum, la revista del Centro de Estudiantes de Filosofía y Letras, y, en junio de ese año, fue electo para conducir dicho Centro. Continuando la labor que había iniciado como arielista, declaró en el primer número de la misma:

Anhelamos que nuestra Revista sea un documento vivo y palpitante de la juventud que milita rumorosa en la Universidad. Y por eso es preciso que los jóvenes dejen oír sus voces expresivas, no sólo en los dominios generales de la Ciencia y de la Filosofía, sino en la aplicación de éstas a todos aquellos órdenes contemporáneos de la vida que nos afectan, con preferencia de nuestro ambiente y de nuestro país. ${ }^{10}$

En los tres números de la revista a su cargo, Bermann buscó que la publicación estudiantil dejara de ser un "canasto de apuntes" o una "revista de corte académico" para convertirse en un instrumento de discusión sobre el lugar de la universidad en la sociedad y, más específicamente, de la construcción de una universidad popular. Así, en el manifiesto que abre el número 35-36, sostiene que "los universitarios, profesores, alumnos y profesionales, sentirán en toda su amplitud el dicho vulgar: "a una mayor cultura, corresponde una mayor capacidad para la acción, más deberes que cumplir"11. Es decir, en los años previos a la Reforma, se ocupó que se vislumbrara la misión de la nueva universidad, que debería perder las características adustas, de privilegio, que le había trasmitido la tradición hispano-colonial, y que, conservando el sentido de un alto instinto de estudio, se acercara al pueblo. De esa manera la Universidad se refundirá con

9 José Luis Fitó, Gregorio Bermann: Reformista, pensador y psiquiatra (Buenos Aires: Proyecto Ensayo Hispánico, 1997-2015), $w$ ww.ensayistas.org/critica/generales/C-H/argentina/bermann.htm. (2 de febrero, 2017).

10 Gregorio Bermann, Revista Verbum, No. 31.

11 Gregorio Bermann, Revista Verbum, Nos. 35-36. 
él y surgirá por encima, del mismo modo que sobresale la cabeza del nadador por arriba de las aguas uniformes.

Este movimiento de renovación de la Universidad tiene, en nuestro sentir, una alta finalidad democrática. La Universidad perderá las características adustas, de privilegio, que le ha trasmitido la tradición hispano-colonial, y conservando el sentido de un alto instinto de estudio, se acercará al pueblo, le servirá con su trabajo espiritual; la Universidad se refundirá con el pueblo, y surgirá por encima, del mismo modo que sobresale la cabeza del nadador por encima de las aguas uniformes, ligeramente encrespadas aquí y allái ${ }^{12}$.

En ese tiempo Gregorio entró en contacto con otros intelectuales y políticos de la época; fue compañero de Alicia Moreau de Justo y por su intermedio conoció y frecuentó a Juan B. Justo. Simultáneamente participó en la fundación de la primera Universidad Libre Argentina.

En síntesis, en los números de la revista a su cargo se perciben los anhelos e ideales que compartirá luego con Deodoro Roca en Córdoba, donde puso de manifiesto su compromiso con los obreros y la nueva misión de los estudiantes en la nueva universidad. Pero no se limitó solo a esta publicación sino que colaboró en otras culturales, científicas y sindicales ${ }^{13}$.

El año de la Reforma Universitaria lo encuentra ejerciendo la presidencia del Centro de Estudiantes, siendo designado además delegado de los estudiantes porteños ante los de Córdoba. En 1919 Gregorio se recibió de médico en la Facultad de Medicina de la Universidad Nacional de Buenos Aires e inmediatamente se desempeñó como tal en el Hospicio de las Mercedes y en una clínica privada.

\section{Gregorio en Córdoba}

En 1921 hace su arribo a Córdoba para ejercer como profesor suplente de la Cátedra de Medicina Legal y Toxicología, siendo siete años más tarde designado profesor titular, cargo en el que permaneció hasta 1936, cuando por avatares políticos fue cesanteado por defender a un amigo, el intelectual Aníbal Ponce que fue exonerado de los cargos docentes que desempeñaba en el Instituto Nacional del Profesorado Secundario, acusado de ejercicio ilegal de la medicina por el gobierno de Justo ${ }^{14}$. Entretanto, en el 22 casó con la profesora Leonilda Barrancos

12 Gregorio Bermann, "Vida universitaria", Revista Verbum, No. 31.

13 Adrián Celentano, El humanismo de Gregorio Bermann (Argentina: Proyecto de Investigación Internacional Pensamiento latinoamericano del siglo XX ante la condición humana, 2006) en www.ensayistas.org/critica/generales/C-H/argentina/bermann.htm. (30 de mayo, 2016).

Natalia Bustelo, "Arielistas, ateneístas, novecentistas Los jóvenes revisteros porteños en los inicios de la Reforma Universitaria", Revista Los Trabajos y los días, Año 04, No. 3 (2012): 12-40.

14 Esto motivó el autoexilio de Ponce en México. En 1938, con motivo del homenaje en memoria de Aníbal Ponce, Deodoro Roca sostuvo que no había sido la Sección Especial la que lo había expulsado del país, sino la cobardía de unos aliados que no habían advertido la naturaleza moral de su figura y el lugar que ocupaba en las letras argentinas: "Ponce era el mejor dotado y el mejor realizado de las últimas generaciones actuantes de la Argentina... Piensa en todo. Y en todo piensa con ese frenético rigor, desde su adolescencia inverosímil... Porque Ponce es de los que siente su obra como parte de su vida, y su vida ligada a la conciencia del deber hacia la libre comunidad de los hombres". Gregorio Bermann, "Aníbal Ponce, delincuente y profesor indigno" en Conciencia 
con quien tuvo tres hijos: Sylvia, una reconocida psiquiatra, Daniel Gregorio, fallecido trágicamente al año y medio de edad, y Claudio, un prestigioso psicoanalista radicado en Barcelona ${ }^{15}$. Su vida amorosa tuvo varios altibajos, el mismo año que perdía su cátedra se separó de su primera esposa. Más tarde, contrajo matrimonio con Isa Kremer, cantante rusa, de Odessa, fallecida en Córdoba en 1956. Luego casó con Dolores Oliva Soaje, música cordobesa que introdujo el método Suzuki para aprendizaje de violín en la Universidad Nacional.

Su amistad con Deodoro Roca, Saúl Taborda, Arturo y Raúl Orgaz y otros intelectuales cordobeses de gran valía, data de los años veinte, década que toda esa generación, estaba inspirada en las ideas del filósofo uruguayo José E. Rodo, José Martí, Rubén Darío y José Ortega y Gasset, entre otros...

En 1929, Gregorio comienza a tener una destacada actividad en la Universidad de Córdoba al desempeñarse como Consejero de la Facultad de Medicina, siendo contemporáneamente miembro del Partido Socialista de Córdoba. Debemos destacar que eran tiempos difíciles para esta ciudad conservadora y católica, que presenció la existencia de "guardias blancas" que salían a la caza de los rusos, que eran considerados maximalistas, y los anarquistas. El clima político no podía ser más difícil y más para él que era de origen judío.

\section{Los difíciles años treinta}

El 6 de septiembre de 1930 se produjo el primer golpe militar en la República Argentina. En el mensaje de ese día Uriburu anunciaba, entre otras cosas, que la revolución venía a restablecer "el orden en las universidades. Por entonces entendía que el desorden era la participación estudiantil y las ideas que circulaban. En consecuencia, lo primero que hizo fue arrasar con lo que la Reforma había tratado de imponer. Luego envió como interventor de la provincia de Córdoba a Carlos Ibarguren ${ }^{16}$. Inmediatamente, a criterio de Deodoro Roca, eso dio pie a que "aparecieran las camarillas, los chanchullos y la entrega de la Universidad a los inmorales y al usufructo de los paniaguados e incapaces"17.

El rector Luis J. Posse, profesor de Derecho Internacional Privado, que había sido elegido por la Asamblea universitaria cuando concluyó la huelga estudiantil de 1928, renunció al cargo aduciendo que "venía a declinarlo para facilitar la renovación de valores que parece imponer la hora actual"18. Durante su corta gestión Posse logró que la calma volviese a la Universidad, después de años de

de nuestro tiempo (Buenos Aires: Editorial Hernández, 1971), 49-56. Ver además “Los Principios 23 de octubre de 1936”, p. 1 col. 5. También en Archivo de Gregorio Bermann, CEA- UNC, Caja 15. Doc. 062.

15 Sylvia falleció en Córdoba el 17 de septiembre de 2012 a los 90 años; y Claudio, en Barcelona en el 2013.

16 Salteño de nacimiento se recibió de abogado en la Universidad de La Plata en 1898 y en 1911 era profesor de la misma, siendo considerado un hombre de prestigio en los ambientes universitarios, etapa que actuó dentro del Partido Demócrata Progresista. Para quien quiera ahondar en el tema de su intervención, consultar Carlos Ibarguren, La historia que he vivido (Buenos Aires: Peuser, 1955). Hay otras ediciones. Marcela B. González, Autoritarismo, corporativismo y fuerzas políticas. La intervención nacional en Córdoba, 1930-1931 (Córdoba: EDUCC, 2008).

17 Deodoro Roca, Obra reunida. I cuestiones universitarias (Córdoba: Universidad Nacional de Córdoba, 2008), 118.

18 La Voz del Interior, 10 de septiembre de 1930, p. 6 col.6. Crónica universitaria año 17 N 7-8, septiembre-octubre de 1930, p. 267. 
enfrentamientos entre reformistas y nacionalistas. Creó la Facultad de Ciencias Económicas, en base de la Escuela Superior de Comercio y la Facultad de Filosofía y Letras, amén de otros interesantes proyectos académicos. Por tal razón los estudiantes iniciaron un movimiento para que su renuncia no fuese aceptada, llegando a juntar cientos de firmas, en particular en las Facultades de Derecho y Medicina, es que rechazaban la idea que el Dr. Antonio Nores, un profesor considerado conservador que estuvo en silencio por largos 12 años, no fuese elegido, como se rumoreaba desde la prensa ${ }^{19}$.

El 19 de septiembre la Asamblea universitaria consideró la renuncia de Posse y su reemplazante fue el ingeniero Eduardo Deheza ${ }^{20}$. Poco después comenzaron las persecuciones y el poder ejecutivo exoneró a varios profesores de la Facultad de Medicina, doctores Jorge Orgaz, Gumersindo Sayago. Tomás de Villafañe Lastra y Gregorio Bermann. Y en la de Derecho a Donato Latella Frías de reconocida adhesión al partido radical y se suspendió a numerosos estudiantes. El Partido Socialista repudió toda subversión y persecución, pero eso no impidió que Bermann fuese preso político de la dictadura junto a otros profesores universitarios, situación que se repitió en otras ocasiones ${ }^{21}$. A raíz de esta situación, la FUBA decretó una huelga de 48 horas en solidaridad y en Córdoba se repudió a los profesores que llegaron a firmar un compromiso con el jefe de policía Montes de denunciar anomalías. Por su parte Roca, en un encendido discurso sentenció que la Universidad estaba en "su cuarto de hora de desvanecimiento y abandono y se entrega, entre suspiros y aires a la contrarreforma, galán cauto y mañoso" 22 .

\section{Bermann y Roca, hermanados por la política}

Entretanto, en 1931 se convocaron las elecciones nacionales, donde triunfó el binomio integrado por Agustín P. Justo-Julio A. Roca (h) y en la provincia de Córdoba se impuso la fórmula Emilio Olmos-Pedro J. Frías. En esa elección los reformistas decidieron participar, Bermann encabezó la fórmula de la Alianza Socialista-Demócrata Progresista, junto a Juan Presaco, siendo candidato a intendente municipal Deodoro Roca, mientras la fórmula nacional la conformaban

19 Años más tarde Deodoro Roca pronunció un discurso en el acto de homenaje rendido a Posse con motivo de su retiro de la cátedra universitaria donde destacó que jamás escondió su saber, ni hurtó su responsabilidad, Cfr. Deodoro Roca, Obra reunida...op. cit., (cita 17), 90 - 94.

20 Horacio Sanguinetti, La trayectoria de una flecha. Las obras y los días de Deodoro Roca (Buenos Aires: Ed. Librería Histórica, 2003), 60-61.

21 María Cristina Vera de Flachs y Antonio Sillau, "Un estudio sobre las luchas políticas e ideológicas de la Universidad de Córdoba, Argentina”, Cuadernos del Instituto Antonio de Nebrija, (2008). La Voz del Interior, 6 de septiembre de 1930, p. 1, c. 6.

Ver también Diana Soto Arango, María Isabel Lafuente. Autonomía y modelos universitarios en América Latina. Tomo II (Bogotá, León. Universidad de León, España, Asociación Colombiana de Universidades. ASCUN. Universidad Pedagógica y Tecnológica de Colombia, RUDECOLOMBIA, 2007).

Diana Elvira Soto Arango "Períodos de reforma universitaria en Colombia de la colonia al siglo XXI". Revista Historia de la Educación Latinoamericana Vol. 16, No. 22 (2014): 277-337.

María Cristina Vera, "Notas para la Historia de la Universidad en Argentina". Revista Historia de la Educación Latinoamericana No. 8 (2006): 65-112.

22 Deodoro Roca, “Juventud y servidumbre”, Diario El País, Córdoba, 14 de junio de 1931. 
Lisandro de la Torre-Nicolás Repetto. En esa oportunidad, la red intelectual del Partido Comunista los acompañó, pues los reformistas despertaban grandes expectativas en Córdoba y a pesar que abundaron denuncias de fraude, nada se pudo hacer para lograr que el grupo triunfara. En ese entonces Bermann sentenció:

Sépase bien que los profesores universitarios de la Reforma no somos burócratas cuyo pensamiento se paga con sueldo, incompatible con la dignidad y el sentido de la cátedra universitaria; no guardarán silencio cobarde ante la injusticia, ni se complicarán con tendencias regresivas ${ }^{23}$.

En 1932, Bermann junto a Jorge Orgaz, fueron acusados por su actuación durante la dictadura. El movimiento estudiantil respondió con movilizaciones y una huelga, que se mantuvo durante casi todo el año hasta lograr la reincorporación de ambos ${ }^{24}$.

En 1933, y como una evidencia más de la violencia política que sacudía la provincia, un grupo de fascistas de la Legión Cívica, en un acto realizado en las calles Belgrano y Achával Rodríguez, asesinó al diputado socialista José Guevara. Una multitud de veinte mil personas, entre quienes estaban Alicia M. de Justo y Alfredo Palacios, acompañó el sepelio. Deodoro, en su discurso de despedida, sentenció que el asesinato no era un hecho que hubiera ocurrido en Córdoba por circunstancias locales y entre conceptos agregó lo siguiente:

No hay que buscar la responsabilidad en el sicario a sueldo que lo consumó, hay que buscar las legiones militarizadas de la clase gobernante, en la clase conservadora, clerical y capitalista, a la cual sirven bajo su inspiración, los asesinos en potencia que forman las legiones militarizadas de la clase gobernante. Y continuó... que estábamos en medio de una gran convulsión y está en juego, incluso, nuestro destino de nación civilizada. ${ }^{25}$

La violencia se mantuvo en los años sucesivos y valga a modo de ejemplo decir que, en 1935, en un pueblito del interior cordobés, Plaza de Mercedes, se produjo un grave enfrentamiento entre manifestantes radicales y la policía, muriendo dos militantes y siete policías. Mientras tanto, ante el fallecimiento del gobernador Emilio Olmos, asumía la gobernación el Vice Dr. Pedro J. Frías.

\section{Latinoamérica en la visión de los reformistas}

Desde fines del siglo XIX, los futuros reformistas americanos tenían idea de propiciar un acendrado latino americanismo; José E. Rodo, Manuel Ugarte y

23 Deodoro Roca, "Juventud y servidumbre”, Revista La Semana Médica, No. 18, (1931): 12

24 Para quien quiera ahondar en el tema de esta huelga estudiantil consultar Leticia Aguirre, La generación del 32. Reforma universitaria. Tomás Bordones (Córdoba: Editorial Universidad de Córdoba, 1989).

25 Deodoro Roca, El difícil tiempo nuevo (Buenos Aires: Editorial Lautaro, 1956), 163-166. 
Rubén Darío, entre otros, incidieron para que las ideas prosperaran entre los jóvenes.

En 1925, Deodoro Roca organizó con el apoyo de intelectuales cordobeses la Unión Latinoamericana, organismo que se proponía enfrentar el imperialismo de los Estados capitalistas y coordinar la acción de los escritores, intelectuales y maestros de América Latina en la "lucha por la reafirmación de la democracia, la abolición de los privilegios económicos, la nacionalización de las fuentes de riqueza, la eliminación de la influencia de la Iglesia en la vida pública y educacional, la extensión de la educación gratuita, laica y obligatoria y la reforma universitaria integral ${ }^{26}$.

Además, Roca, desde la ciudad de Córdoba al término de la Guerra del Chaco, reunió a un grupo de dirigentes del proceso reformista junto a exiliados bolivianos y paraguayos para conformar el Comité Pro-Paz y Libertad de América (CPPYLA). Entidad surgida unos meses antes al calor del clima antibelicista que, desde Córdoba, acompañó las negociaciones diplomáticas que pusieron fin a dicha Guerra, entre Paraguay y Bolivia iniciada en 1932. La misma estuvo liderada por Deodoro Roca, Enrique Barros y Gregorio Bermann -tres figuras centrales del reformismo universitario cordobés. En su manifiesto inaugural de abril del '35, dirigido a los intelectuales, obreros estudiantes y maestros de Latinoamérica, el Comité sintetizaba su programa en un llamado a "la paz del Chaco, por la defensa de las libertades democráticas en el continente y por su liberación del imperialismo", al tiempo que hacía votos por el inicio de una "campaña impostergable" que debía culminar en una gran conferencia de fraternidad de los pueblos de Latinoamérica, a realizarse en Buenos Aires y, paralelamente con grandes demostraciones populares en todas las ciudades del continente, exigiendo la paz"27.

En los primeros meses de 1935 las tratativas diplomáticas de paz, encabezadas por el Ministro de Relaciones Exteriores del gobierno argentino Carlos Saavedra Lamas, habían otorgado a la guerra boliviano-paraguaya un lugar de primer orden en la agenda pública argentina. Cotidianamente, las principales páginas de los grandes periódicos traían consigo tanto informaciones de las alternativas de la contienda bélica, como de los pormenores de las negociaciones de paz. En ellas descolló tempranamente el canciller argentino, quien en 1933 había impulsado la firma de un Tratado anti bélico de no-agresión y de conciliación con el fin de evitar nuevos conflictos en el continente. Y a mediados de 1935, sus hábiles gestiones diplomáticas crearon las condiciones para que la Conferencia de paz celebrada en Buenos Aires y que concluyó, el 12 de junio de ese año, pusiera fin a la guerra. La firma del cese de hostilidades fue acompañada por manifestaciones de júbilo en todo el continente ${ }^{28}$.

26 Acta de la fundación de la Unión Latinoamericana, reproducida en Alberto Ciria y Horacio Sanguinetti, La Reforma universitaria, vol. I, (Buenos Aires: CEAL, 1987), 69-70.

27 Comité Pro Paz y Libertad de América, “¡Por la paz de América!”, en El difícil tiempo nuevo, op. cit., (cita 25), 236.

28 Como es sabido, la actuación de Saavedra Lamas en la resolución de la contienda determinaría que apenas un año después le fuera concedido el Premio Nobel de la Paz. 
El 2 de noviembre de 1935 Roca fundó la revista Flecha por la paz y la libertad de América, que salió a la luz como órgano del (CPPYLA) ${ }^{29}$. Decepcionado de su paso por la política en 1936, decidió abocarse a elaborar una encuesta en dicha Revista sobre la suerte de la Reforma universitaria. La encuesta fue respondida por los principales referentes de ese movimiento, a saber: Enrique Puccio, Saúl Taborda, Juan Filloy, Carlos Brandán Caraffa, Juan Zanetti, Horacio Miravet, Antonio Navarro, José Martorelli, José Benjamín Barros, Jorge Orgaz, Dardo Cúneo, Paulino González Alberdi, Alberto May Zubiría, Vicente Mocciaro, Ismael Borda behere, Sergio Bagú, Raúl Orgaz, Marcos Meerof, Enrique Barros, Adelmo Montenegro, Tomás Bordones y el propio Deodoro Roca. Se expresaron también, pero sin atenerse a las preguntas sino bajo la forma de artículos, Gregorio Bermann, Julio V. González, Juan Lazarte, Héctor Pablo Agosti, Santiago Monserrat, Francisco Deffis ${ }^{30}$ y el diario Los Principios que lo hizo en uno titulado a "18 años vista". En esa oportunidad Bermann, al igual que Roca planteó su mirada crítica al sostener que la misma

...no ha sido lograda y cuyos primeros sillares apenas se han colocado". Él era partidario de que al menos la Reforma fijara los cimientos de las directivas culturales del nuevo tiempo, ya que difícilmente lograría estructurar una doctrina social propia. Según él, si bien todos los movimientos de juventud fracasaron, especialmente en sus aspiraciones, el movimiento reformista de Córdoba estaba destinado a triunfar porque... conjuga dialécticamente la verdadera doctrina social con la cambiante realidad en la férvida biosociología de edad juvenil ${ }^{31}$.

En este sentido, al decir de Bermann, la edad juvenil había sido menospreciada, incomprendida, pero cuando llegaba la hora de sacrificio y heroísmo, "¡cuántos elogios se lleva!". Por eso, para algunos se hacía necesario entenderla en sí misma ${ }^{32}$. Los párrafos precedentes demuestran que ambos amigos estaban decepcionados por los fracasos del movimiento reformista y además recordemos que aquel había sido exonerado de la Universidad acusado de inconducta y de participar con agitadores y comunistas notorios en la destrucción del orden social $^{33}$.

29 Ricardo Pasolini, "El nacimiento de una sensibilidad política. Cultura Antifascista, comunismo y nación en la Argentina: entre la AIAPE y el Congreso Argentino de la Cultura, 1935-1955”, en Desarrollo Económico 45, No. 179 (2005). Andrés Bisso, Acción Argentina. Un antifascismo nacional en tiempos de guerra mundial, (Buenos Aires: Prometeo, 2005).

30 Deffis compartiría la dirección con Roca de la revista Las Comunas en 1939-40.

31 Revista Flecha, Córdoba, 1936. María Cristina Vera de Flachs, "Reformas y contrarreformas y movimientos estudiantiles en la Universidad de Córdoba, 1870-1936", en Movimientos estudiantiles en la historia de América Latina, III, eds. Renate Marsiske (México: Universidad Nacional Autónoma de México, 2006), 21-81. Marcela B., González "Fines y logros de la reforma Universitaria. Visión retrospectiva de sus protagonistas de la encuesta de Flecha" en XII Congreso internacional AHILA IV (2011): 221-229.

32 Los argumentos esbozados entonces serán retomados en 1946, cuando publicó en México su obra titulada Juventud de América, inserta el movimiento del nuevo mundo en el marco de los movimientos juveniles y estudiantiles europeos desde el siglo XIX, pensados alrededor de las revoluciones de 1848 o sea en el proceso de las revoluciones republicanas y democráticas, donde las irrupciones proletarias atrajeron la atención de los jóvenes estudiantes alemanes, franceses e italianos. Gregorio Bermann, Juventud de América (Buenos Aires: Gleizer, 1946), 249.

33 Los Principios, Córdoba, 18 de diciembre de 1936, p. 6 col. 3. 


\section{Los sucesivos viajes de Bermann y su regreso a Córdoba}

En marzo de 1937 Gregorio junto a Rafael González Tunón decide partir nuevamente de viaje a España con la idea de colaborar con las Brigadas Internacionales que, desde distintos países, participaron de la defensa de la República española contra el golpe de Franco. Roca había sido invitado para ser de la partida, pero ya se encontraba con problemas de salud, lo que lo hizo desistir. Desde Madrid Bermann enviaría distintas colaboraciones a periódicos y revistas argentinas ${ }^{34}$ y publicó Dialéctica del fascismo y su psicopatología, libro donde combinó su militancia antifascista con su actividad científica. Durante la guerra civil española actuó como jefe de la misión argentina del servicio de Neuropsiquiatría en el Hospital Militar Nro. 6 de Madrid, como comandante médico. Durante ese tiempo no hay registros de correspondencia con Roca ${ }^{35}$.

En 1938, de regreso a Córdoba, formó parte del grupo de intelectuales progresistas más destacados lo que lo llevó a reunirse permanentemente, entre otros, con Alfredo Martínez Howard, Rafael Alberti y su pareja María Teresa León, con su amigo Deodoro y con la que luego sería su segunda esposa Isa Kremer. En 1942 editó el libro titulado Las neurosis en la guerra, donde analizó los efectos de la guerra civil, manteniendo discusiones con otros médicos sobre el tipo de terapia a emplear. Al año siguiente fue encarcelado nuevamente por el segundo golpe militar que se llevó a cabo en la Argentina. Al ser liberado, dejó transitoriamente el país y viajó por EEUU y Gran Bretaña para integrarse, en 1945, como médico sanitarista de las Naciones Unidas y participar como miembro fundador de la Organización Mundial de la Salud.

En 1946 salió a la luz su obra titulada Juventud de América como resultado de los "aportes" que los acontecimientos internacionales - fascismo, nacional socialismo, franquismo, Segunda Guerra Mundial- y nacionales como golpe militar y surgimiento del peronismo- le permitieron una mirada crítica respecto de la función de la juventud en ese tiempo ${ }^{36}$. A posteriori sigue viajando permanentemente, junto a Ezequiel Martínez Estrada, paciente suyo, viajó en 1969 a China especialmente invitado para la celebración de los 20 años de la Revolución. Y por América Latina donde dictó conferencias y cursos.

Fue además fundador de la Asociación Psiquiátrica de América Latina que presidió varios años y siempre preocupado por el tema de su especialidad, escribió varios libros y artículos, aunque no descuidó los relacionados con la filosofía y la política ${ }^{37}$. Su evolución doctrinaria puede seguirse a través de sus escritos. Es allí donde el lector interesado podrá palpar la intensa pasión, la curiosidad

34 Entre otras, Revista Médica, La Semana Médica, La Medicina Argentina, del Colegio Médico de Córdoba, diarios Crónica, El País, La Vanguardia, La Prensa y La Nación.

35 Juan de la Cruz Arganaraz, El freudismo reformista 1926-1976 en la literatura y la medicina, (Córdoba: Editorial Brujas, 2007$), 104$.

36 Gregorio Bermann, "La juventud argentina en Córdoba a los hombres libres de Sud América", en La Reforma Universitaria 19181930. (Caracas: Editorial Biblioteca Ayacucho, 1941). Gregorio Bermann, Juventud en América, op. cit., (cita 32), 249.

37 Su archivo personal expone una serie de documentos importantes, incluye misivas, manuscritos, notas mecanografiadas, pequeños escritos que dan a conocer el universo del personaje. Se puede consultar en el Centro de Estudios Avanzados de la Universidad Nacional de Córdoba y lo componen 8.808 unidades. Estas cartas no se incluyen en él. 
insaciable, la vasta cultura y el ideario filosófico que, de manera amena, pero sin concesiones, fue desgranando con gran soltura. En 1960 editó Nuestra psiquiatría donde reunió varios de sus escritos, sobre todo los más polémicos ${ }^{38}$.

Falleció en Córdoba en 1972, su vida está atravesada por el protagonismo de dos generaciones claves en la historia argentina del siglo XX. Una, constituida alrededor de la Reforma Universitaria en 1918 y, como profesor universitario en la cátedra de Toxicomanía y Medicina Legal en la Universidad de Córdoba y, la otra, por su interés por la política, primero como socialista y luego como marxista. Al finalizar su vida ambos intereses enuncian la relación entre intelectuales y política alrededor de la tarea de transformar la sociedad emancipando a los sectores populares ${ }^{39}$. Es decir, su línea política no puede separarse de su concepción de la ciencia: ambas fueron articuladas originalmente por el positivismo, combinado con el marxismo y otras vertientes filosóficas (determinismo, psicoanálisis, espiritualismo, etc.) donde podemos encontrar fundada la concepción humanista de Bermann, temas que le preocuparon tempranamente ${ }^{40}$.

\section{Análisis de la correspondencia de Gregorio Bermann a Roca}

En carta fechada en Buenos Aires, el 14 de septiembre de 1918, Bermann en un tono amistoso, ya que la encabeza con "mi estimado Roca", menciona una actitud de la Federación Universitaria (FUBA) y del Comité Córdoba a raíz de una huelga de los trabajadores tranviarios. Recordemos que en esa época no existía un movimiento obrero organizado en Córdoba, pero sí se constataba la presencia de una larvada militancia sindical, que incorporaba las directrices que llegaban a Córdoba desde Buenos Aires, donde activistas sindicales de extracción socialista, anarco sindicalistas y anarquistas, pugnaban por obtener supremacía a través de las diferentes divisiones de la Federación Obrera Regional Argentina, FORA. Pero todavía no tenía esa organización la fuerza suficiente como para exhibirse en un plano de lucha abierta por sus reivindicaciones.

Respecto a esa actitud menciona la prisión de los reformistas, el catamarqueño Horacio Valdez y el riojano Enrique Barros detenidos el 9 de septiembre a raíz de la ocupación de la Universidad y le pide que le ampliara las causas y circunstancias de la detención, ya que la FUBA haría actos públicos y necesitaba contar con esa información para saber a qué atenerse y con qué criterios realizar dichos actos, solicitándole a Deodoro cierta prudencia ${ }^{41}$. Aclarándole que mantendrá la confidencialidad de la información que reciba. Opina también sobre el curso de los acontecimientos en relación a la causa estudiantil, y manifiesta que

38 Gregorio Bermann, Nuestra Psiquiatría (Buenos Aires: Paidós, 1960). Luego publicó La salud mental y la asistencia psiquiátrica en la Argentina (Buenos Aires: Paidós, 1965).

39 Adrián Celentano, "El humanismo de Gregorio Bermann", op. cit., (cita 13).

40 Tempranamente en 1920 escribió: Gregorio Bermann, El determinismo en la ciencia y la vida, (Buenos Aires: Sociedad Cooperativa Nosotros, 1920). Gregorio Bermann, "El difícil tiempo nuevo a través de Deodoro Roca", en Cuadernos Americanos, año XVI, (1957).

41 Recordemos que ambos, junto a Ismael Bordabehere eran los máximos dirigentes estudiantiles de Derecho, Medicina e Ingeniería, respectivamente. Y que entre los tres tendrían la potestad de designar profesores interinos. 
repita "a los compañeros de causa cuán inquebrantable es nuestra solidaridad". Asimismo, solicita le entregue un sobre (una carta) a Barros.

- A raíz de estas circunstancias, el gobierno nacional enviará a Córdoba al ministro de justicia e instrucción pública José S. Salinas como interventor de la Universidad. Los jóvenes detenidos y acusados de sedición fueron liberados días después y las causas quedaron sin efecto. Los estudiantes aplaudieron la obra del interventor quien, entre otras atribuciones modificó los estatutos de la Casa de Trejo, lo que trajo como consecuencia el levantamiento de la huelga declarada el 15 de junio por tiempo indeterminado y a partir del 17 de octubre se reabrieron las clases disponiéndose la reforma de los planes de estudio.

Se despide Bermann con la siguiente frase: "mi buen amigo, un fuerte apretón de manos". Como señalaba un periódico de la época, los jóvenes estudiantes pensaban que a partir de entonces:

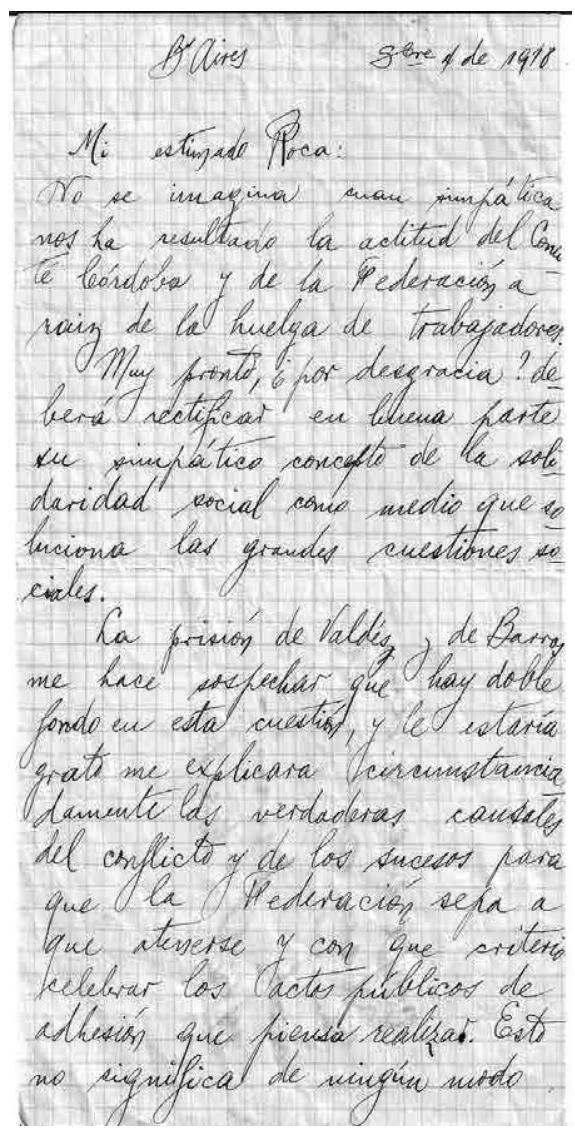

Fuente: Copia facsimilar de la primera carta de Bermann a Roca.
La monarquía ha muerto y esta es la hora de regocijo para el país, porque la democracia bifronte, ejerce ya su mandato republicano en la nueva universidad" ${ }^{42}$.

Por otra parte, cabe recordar que recién fue en el primer mes de 1919 cuando se registra quizá el primer contacto entre estudiantes y obreros, al hablar Deodoro Roca en una asamblea de la Sociedad de Ayuda Mutua de los Obreros Panaderos llevando la adhesión de la Federación Universitaria a la huelga que estaba realizando ese colectivo de trabajadores. Como gesto de reciprocidad el dirigente obrero Miguel Contreras dirigió la palabra en una asamblea de la FUC, donde se pronunció por la solidaridad con aquellos huelguistas.

La segunda carta de Bermann a Roca está escrita desde Choele Choel, Provincia de Rio Negro, y fechada el 23 de enero de 1919 y en ella vuelve a manifestarle su amistad. Le comenta que se enteró de la venganza de los radicales al eliminarle de la Dirección del Museo Provincial, cargo que Deodoro venía ejerciendo satisfactoriamente desde el 31 de julio de 1916. Gracias a su gestión la provincia pudo frenar

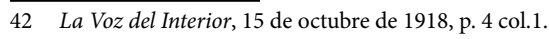


la demolición de la importante casona conocida como la casa del marqués de Sobre Monte y adquirir una importante colección de antigüedades que perteneció a su antiguo director Jacobo Wolff ${ }^{43}$.

Transcripción de la esquela del Dr. Gregorio Bermann (letra impresa, también aparece, al pie de la tarjeta la dirección Corrientes 2446)

"Mi estimado Roca:

Me he enterado de la torpe venganza de esos mezquinos radicales, al eliminarle de la dirección del Museo. Lo siento por el Museo que perderá así en estética y dignidad.

Vd. habrá sentido tan profundamente como yo lo que significaron los últimos acontecimientos; ha sido una tentativa de la Santa Alianza para herir de muerte a las energías jóvenes que marchan esforzadamente a la conquista de un porvenir de mayor bien y justicia. Oscuros nubarrones han velado por un momento el horizonte nacional. Por un momento, nada más. Ya sufrirán nuestra réplica vigorosa. Y Vd., como siempre, uno de los primeros en la brecha. Reciba por ello mi vehemente aplauso y un saludo cariñoso de su amigo".

G. Bermann (firma)

En Choele Choel, Á 29/1/1919

\section{(Al anverso) \\ Dr. GREGORIO BERMANN (letra impresa) \\ Dr. Deodoro Roca \\ Mi caro amigo:}

Se me ha informado que esta $\mathrm{Vd}$. enfermo hace tiempo ¿Es verdad?, ¿Ya está sano? Desearía saberlo, y se lo desea fervientemente su amigo

G. Bermann (firma)

\section{(Al reverso)}

Nota: especial.

"Estamos en un momento de dolor para las ideas nuevas. Cada vez voy descubriendo cosas nuevas en esta, nuestra psicología tan especial.

Entre otras debo comunicarle una buena noticia: Korn Villafañe se dispone a hacer la Revolución social desde el Gobierno y predica una cruzada contra Alberdi a quien acusa de los males de nuestra civilización materialista. Todo si ("llega"tachado) le hace Pte. del C. E de Derecho.

43 Wolff emigró tempranamente de Alemania abriendo su consultorio en Córdoba en 1899. Integró la institución cultural El Ateneo de Córdoba y colaboró con el Museo Politécnico Provincial del que fue su director hasta 1911 y se desempeñó como cónsul honorario de Alemania. Falleció en Buenos Aires en 1917. 
Como puede observarse en la transcripción que adjuntamos up supra, Bermann aprovechó el reverso de su esquela para hacer una manifestación política al mencionar un momento difícil para las ideas nuevas, de allí que habla de "nuestra psicología tan especial", suponemos se refiere a los argentinos. No obstante cree que tiene una buena noticia: Korn Villafañe "se dispone a hacer la Revolución Social desde el Gobierno" y predica una cruzada contra Alberdi a quien acusa de los males de nuestra civilización materialista ${ }^{44}$. Condiciona este plan de acción, si él llega a ser elegido Presidente del Centro de Estudiantes de Derecho. Recordemos que Korn Villafañe es un hombre de la generación novecentista contrario al positivismo predicado por Sarmiento, Alberdi y Mitre. Los principios compartidos: el anti positivismo y el interés centrado en desplazar a sus cuadros de las cátedras universitarias hablan de la convicción de los jóvenes que era esta una batalla generacional; y el privilegio de estos acuerdos en las notas programáticas del novecentismo. En su despedida le reitera: fervientemente, su amigo.

\section{Los conflictos sociales y la juventud universitaria}

- Desde diciembre de 1918 una oleada de huelgas se desató en todo el país, lo que se acrecentó en enero de 1919 a raíz de una declarada en los Talleres Vasena por mejores condiciones laborales. El conflicto fue en continuo ascenso hasta que grupos parapoliciales asesinaron a cientos de personas, incluyendo lo que se conoce como el único pogromo [matanza de judíos] en América. En Córdoba, Rosario y otras ciudades del interior hubo ecos de esas protestas iniciadas en Buenos Aires. En esta carta, Bermann menciona a la "Santa Alianza" como la que "intenta herir de muerte a las fuerzas juveniles que van a la conquista de un porvenir de bien y justicia". Llama a la acción contra esas fuerzas ("nuestra réplica") y menciona a Deodoro como uno de los primeros que llevarán a cabo esa tarea.

- Tal como señalaba Bermann, en un comunicado oficial del 23 de enero de 1919, el gobierno de la provincia de Córdoba decretó la exoneración de Roca de su cargo de director del Museo Provincial, argumentando un informe elevado por el sub intendente de policía, “...con motivo de los sucesos ocurridos el día 14 del corriente; y desprendiéndose de ellos que el Doctor Roca, "ha adoptado actitudes incompatibles con su carácter de empleado público" ${ }^{45}$.

Evidentemente el apartamiento del cargo de Deodoro se produjo después de su participación activa en la huelga conocida como "Semana Trágica", lo que fue objetado por algunos sectores clericales y por otras cuestiones menores. Por eso no llama la atención que fuese reemplazado, por decreto del gobernador radical Julio C. Borda, por el presbítero Pablo Cabrera. No obstante, cabe destacar que este decidió mantener el proyecto de especialización museológico delineado por

\footnotetext{
44 Korn Villafañe es considerado como el iniciador del pensamiento filosófico en la Argentina y como uno de "los cinco sabios" de la ciudad de La Plata, junto a Ameghino, Pedro Bonifacio Palacios, alias Alma fuerte y Carlos Spegazzini.

45 Ubicado Bibliorato II, Apartado M documento 7.
} 
Roca. Podemos certificar esta intención en la carta que el Capellán le remite a Deodoro con fecha 12 de marzo y donde le dice:

"Sabía de los interesantes proyectos ideados acariciados por Ud. en beneficio de nuestro Museo Provincial, proyectos que aplaudo desde el primer momento, como lo sabe su autor. Deploro, sin embargo, -muy a pesar de los votos formulados por Ud.,que mi presencia, quizás sólo transitoria al frente de la mencionada institución, no me permitirá tal vez llevarlos a cabo" ${ }^{\prime \prime 6}$.

- Otros amigos de Roca en solidaridad ante esta exoneración, le enviaron cartas y telegramas de como por ejemplo el firmado por el presidente del Ateneo Universitario de Buenos Aires, Horacio Pozzo y su secretario Julio Malarino ${ }^{47}$. O la carta de Julio V. González (entonces secretario de la FUA) fechada el 26 de enero de 1919 donde en tono irónico lo felicita "por esta destitución que tanto lo honra", agregando "... así como hay nombramientos que rebajan, hay destituciones que realzan".

La tercera carta de Bermann que comentamos, se trata de una pequeña esquela que en su anverso le manifiesta a su "caro amigo" su preocupación por su salud al enterarse que está enfermo. La misma no tiene fecha ni origen, aunque hemos deducido su fecha aproximada en tanto en el corpus documental en el que está incluida, hay otras misivas donde aparece mencionado el tema de la salud de Deodoro ${ }^{48}$.

En efecto, hay varias otras cartas que se incluyen que manifiestan la preocupación de los amigos por la salud de Deodoro. Por ejemplo, en una nota firmada por C. Cisneros Malbrán se inquieta por su estado de salud diciéndole: "no he sabido de tu enfermedad, y tu carta de ayer me hace conocer que hace días te encuentras en cama" ${ }^{\prime 4}$. Por su parte, Arturo Capdevila envía otra donde le señala:

mi querido Deodorisimus: Hablé ayer con tu médico. No te aflijas más. Dice, en suma, el Dr. Villalba que en efecto tú has mejorado, a pesar de que persiste lo que él ha dado en llamar "pérdida de fosfatos". Cree que, si te ajustas por quince días más al régimen que te ha prescripto, puedes venir y dar tranquilamente tus clases. Mándanos ya mismo la nueva solicitud de licencia. Villalba insiste mucho en que te ciñas a su régimen, $y$, sobre todo, hijo mío, en que hagas una vida sobria. Al buen entendedor... ${ }^{50}$

46 Bibliorato II Apartado C documento 10. Adjunto con el documento anterior, Bibliorato II Apartado M documento 6 aparece la notificación a Deodoro del decreto $N^{\circ} 21$ del Ministerio de Gobierno, Justicia Culto e Instrucción Pública, con fecha 24 de enero de 1919.

47 Cf. Bibliorato II Apartado G documento 5.

48 Este material está clasificado en el apartado C documento 14 en el Bibliorato II que contiene correspondencia recibida por Deodoro Roca entre los años 1917, 1918 y 1919. En ese mismo apartado C, el documento 9 hay una carta firmada por Cisneros Malbrán, sin fecha, pero donde se menciona su enfermedad y un documento con fecha 12 de marzo de 1919, que es en una extensa carta enviada por el Capellán Pablo Cabrera, donde aparece la preocupación por su enfermedad.

49 La carta está escrita en papel membreteado que dice Raúl Cisneros- Ingeniero Civil, nombre que está tachado. Bibliorato II Apartado C documento 9 , sin fecha.

50 Bibliorato II Apartado C documento 13, fecha 29 de abril de 1919. 
El certificado médico del Dr. Aquiles D. Villalba (enfermedades internas y del (estómago) su médico de cabecera comenta que:

ha examinado sus orinas: nada de particular a no ser que aún persiste la pérdida de fosfatos" también le envía la medicación "por lo tanto le mando fitina: para que tome dos cucharadas al día". Y le recomienda "creo que debe pasar un tiempo más de reposo antes de entregarse a la intensa labor e iniciar ésta, muy paulatinamente... ${ }^{51}$.

Recordemos también que el Capellán Cabrera le había escrito a Deodoro el 12 de marzo de 1919 y en su parte final dice: "hay algo todavía que lamento con no menor intensidad, el mal estado de su salud. Hago votos pues, por su pronto y fecundo restablecimiento" 52 . Efectivamente, en un lapso breve Deodoro recuperó su salud, aunque dado a sus descuidos y excesos no fue un hombre de larga vida.

\section{CONCLUSIÓN}

La correspondencia analizada nos permite constatar la amistad entre Bermann y Roca a lo largo de sus vidas, la preocupación por la cuestión universitaria, los problemas de la generación del 18 y el mundo de la época. Las otras cartas que mencionamos sirven para reafirmar lo que de ellas se desprende, fueron escrita por hombres jóvenes que pensaron y creyeron en el poder renovador de sus ideas que están presentes en sus manifestaciones políticas, a veces, con distintos matices, pero siempre enfrentado al espíritu monástico y en la calle hermanado, al menos sentimentalmente con el sector obrero.

En relación al vínculo de amistad, podemos subrayar el tono amable, sincero, comprometido entre el personaje estudiado y Roca, hombres que irrumpieron en la escena política de nuestro país, pero que aquí muestran su costado más humano, expresado desde la intimidad que surge en la relación amigo a amigo.

Por otro lado, aparece con claridad y de manera expresa, la pasión que pusieron estos hombres en abrazar las causas y las luchas que llevaron adelante. No hay medias tintas en las afirmaciones expresadas en estas cartas enviadas al "amigo Deodoro". Podemos distinguir en estas un hombre preocupado por su pensamiento político y las ideas que lo sustentan. De estos textos se desprende que ambos son hombres inquietos, que hicieron foco en la cuestión universitaria, en los temas sociales y en la política, con una gran consciencia de las implicancias que estas luchas conllevaban en su seno.

Para finalizar, solo nos resta decir que tenemos un gran desafío entre manos para futuros trabajos sobre el material recibido, sobre todo teniendo en cuenta

51 Bibliorato II Apartado TUV documento 15. Prescripción médica del Dr. Villalba detallando la dieta desde el día 23,24 y 25 en mismo papel membreteado de receta y diagnóstico anterior. Bibliorato II Apartado TUV documento 17. Libreta con Régimen alimenticio para el enfermo entregada por el Dr. Villalba adjunta a los documentos anteriores. ..." Bibliorato II Apartado TUV documento 18.

52 Bibliorato II Apartado C documento 10. 
que se acercan los 100 años de la Reforma. Tomar en nuestras propias manos estas cartas nos ha llevado a adentrarnos en el tiempo a los años de la segunda década del siglo XX, en que irrumpió la Reforma del 18. La significación del medio de comunicación (escrito en papel, manuscrito, en tinta, vía correo) para esa época, alcanza entonces nuevas dimensiones desde las cuales, estas cartas nos hablan, estas cartas nos dicen...

\section{FUENTES}

Archivo del Dr. Gregorio Bermann. CEA- UNC.

Caja 15, Documentos varios.

Documentos Inéditos de Deodoro Roca. Papeles privados.

Periódicos y Revistas

El País, junio de 1931. Periódico de Córdoba

La Voz del Interior, 1918, 1919, 1922, 1930. Periódico de Córdoba.

Los Principios, 1918- 1932

Revista Todo es Historia, Buenos Aires, No. 371 y 438.

Revista La semana Médica

Revista Flecha, 1936.

\section{REFERENCIAS}

Andréu, Abela Jaime. "Las técnicas de Análisis de Contenido: Una revisión actualizada". Fundación Centro Estudios Andaluces. Departamento de Sociología 10, no. 2 (2000):1-34.

Argañaraz, Juan de la Cruz. El freudismo reformista 1926-1976 en la literatura y la medicina. Córdoba: Editorial Brujas, 2007, 104.

Bermann, Gregorio. "El difícil tiempo nuevo a través de Deodoro Roca", en Cuadernos Americanos, año XVI, 1957.

Bermann, Gregorio. La salud mental y la asistencia psiquiátrica en la Argentina. Buenos Aires: Paidós, 1965.

Natalia Bustelo. "Arielistas, ateneístas, novecentistas. Los jóvenes revisteros porteños en los inicios de la Reforma Universitaria", Revista Los Trabajos y los días, Año 04, No. 3 (2012): 12-40.

Candelaresi, Ana María y Rubén Adrián Jaime. "Gregorio Bermann: ideario y acción de la juventud reformista de 1918: vigencia y proyección en la actualidad". (Ponencia presentada en "I Congreso internacional de pensamiento latinoamericano: la construcción de América Latina", Colombia, 19 al 24 de noviembre, 2001).

Celentano, Adrián. El humanismo de Gregorio Bermann. Argentina: Proyecto de Investigación Internacional. Pensamiento latinoamericano del siglo XX ante la condición humana, 2006. www. ensayistas.org/critica/generales/C-H/argentina/bermann.htm. (30/05/2016).

Celentano, Adrián. "Gregorio Bermann: un intelectual entre la Universidad, la psicología y la política". (Ponencia presentada en IV Encuentro Nacional y I Latinoamericano "La universidad como objeto de investigación", Argentina, 6, 7, 8, 9 de octubre, 2004).

Ciapuscio, Guiomar. Tipos textuales, Enciclopedia Semiológica. (Buenos Aires: Facultad de Filosofía y Letras, Universidad de Buenos Aires, 1994).

Doll Castillo, Darcie. "La carta privada como práctica discursiva: Algunos rasgos característicos". Revista signos 35, No. 51-52, (2002): 33-57.

Fitó, José Luis. Gregorio Bermann: Reformista, pensador y psiquiatra. Buenos Aires: Proyecto Ensayo Hispánico, 1997-2015. www.ensayistas.org/critica/generales/C-H/ argentina/ bermann.htm. (02/02/2017). 
González, Marcela B. “Fines y logros de la reforma Universitaria. Visión retrospectiva de sus protagonistas de la encuesta de Flecha". XII Congreso internacional AHILA IV, (2011): 221-229.

González, Marcela B. Autoritarismo, corporativismo y fuerzas políticas. La intervención nacional en Córdoba, 1930-1931. Córdoba: EDUCC, 2008.

Ibarguren, Carlos. La historia que he vivido. Buenos Aires: Peuser, 1955.

Kohan, Néstor. Deodoro Roca, el hereje. Buenos Aires: Biblios, 1999.

Mozejko, Danuta Teresa y Ricardo Lionel Costa. "Producción discursiva: diversidad de sujetos". En Lugares del decir. Competencia social y estrategias discursivas. Rosario: Homo Sapiens, 2002.

Roca, Deodoro. Las obras y los días, al cuidado de Santiago Monserrat. Buenos Aires: Losada, 1945.

Roca, Deodoro. Escritos sobre la Universidad. Córdoba: Universidad Nacional de Córdoba, 2007.

Roca, Deodoro. Obra reunida. I Cuestiones Universitarias. Córdoba: Universidad Nacional de Córdoba, 2008.

Riquelme, Norma Dolores y María Cristina Vera. Historia de Córdoba, Tomo V. Córdoba: en imprenta, 2016.

Sanguinetti, Horacio. La trayectoria de una flecha. Las obras y los días de Deodoro Roca. Buenos Aires: Librería Histórica, 2004.

Sanguinetti, Horacio. “La Reforma Universitaria: 1918-1998”. Todo es Historia, no. 371, (1998): 56-71.

Thompson, John B. La media y la modernidad. Una teoría de los medios de comunicación. Barcelona: Paidós, 1998.

Soto Arango, Diana y Lafuente, María Isabel. Autonomía y modelos universitarios en América Latina. Tomo II Bogotá, León. Universidad de León, España, Asociación Colombiana de Universidades. ASCUN. Universidad Pedagógica y Tecnológica de Colombia, RUDECOLOMBIA, 2007.

Soto Arango, Diana. "Periodos de reforma universitaria en Colombia de la colonia al siglo XXI", Revista Historia de la Educación Latinoamericana 16., No. 22, Vol. 16. (2014): 277-337.

Vera De Flachs, María Cristina, "Notas para la Historia de la Universidad en Argentina”. Revista Historia de la Educación Latinoamericana No. 8 (2006): 65-112.

Vera De Flachs, María Cristina y Antonio Sillau Pérez. “Una puja política ideológica entre nacionalistas y reformistas en la Universidad de Córdoba en los años treinta". En Pasado y presente. Algo más sobre los italianos en la Argentina. Córdoba: Editorial Báez, 2008.

Vera De Flachs, María Cristina y Antonio Sillau Pérez. “Un estudio sobre las luchas políticas e ideológicas de la Universidad de Córdoba, Argentina". Cuadernos del Instituto Antonio de Nebrija, (2008).

Vera De Flachs, María Cristina y Antonio Sillau Pérez. “Ideología y política. Docentes y estudiantes en el contexto de la crisis liberal Argentina. El caso de la Universidad de Córdoba. 1930-1943". Revista de Historia de la Educación Latinoamericana, no. 12, (2009).

Vera De Flachs, María Cristina. "Reformas y contrarreformas y movimientos estudiantiles en la Universidad de Córdoba, 1870-1936". En Movimientos estudiantiles en la historia de América Latina, III, editado por Renate Marsiske. México: Universidad Nacional Autónoma de México, 2006, 21-81.

Vera De Flachs, María Cristina, Jorge y Esmeralda Gaiteri. “Gregorio Bermann y Lisandro de la Torre a Deodoro Roca". Revista de la Junta Provincial de Historia de Córdoba, no. 29, (2017):109.

Vera De Flachs, María Cristina. El epistolario de Gregorio Bermann y de otros "cachorros de la reforma" a Deodoro Roca. Córdoba: inédito, 2017.

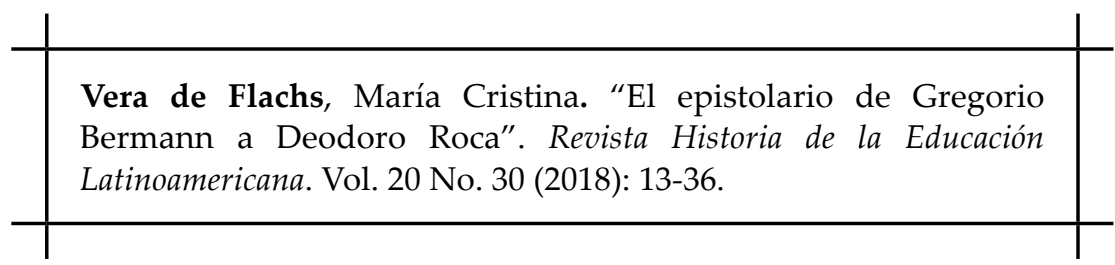

